\title{
INTRATHECAL STREPTOMYCIN AND CEREBROSPINAL GLUCOSE ESTIMATION
}

\author{
BY \\ M. J. H. SMITH \\ From the Department of Chemical Pathology, King's College Hospital Medical School, \\ London
}

(RECEIVED FOR PUBLICATION JANUARY 1, 1952)

The determination of cerebrospinal fluid glucose is important in the diagnosis and prognosis of tuberculous meningitis. The restoration to normal of the characteristically low glucose values is considered to reflect the success of streptomycin therapy. Intrathecal injection of the antibiotic is usually employed in tuberculous meningitis, and attention has been drawn to the fact that streptomycin itself has reducing properties (Cruickshank, 1951) and may interfere with the accurate measurement of cerebrospinal fluid glucose. Alvaro and Nicola (1948), using the HagedornJensen method, reported that various streptomycin preparations were strongly reducing, and that $1 \mathrm{mg}$. of anhydrous streptomycin base was equivalent to values up to $4.5 \mathrm{mg}$. of glucose. It was stated by Wilson (1951) that the intrathecal injection of antibiotics may give temporary false sugar values, so that estimations carried out during and for an indeterminate time after this form of treatment are invalidated.

These considerations suggested an investigation of the reducing powers of streptomycin and dihydrostreptomycin with special reference to the method of measuring cerebrospinal fluid glucose (Nelson, 1944) used in this laboratory. In addition, cerebrospinal fluid glucose results from a number of cases of tuberculous meningitis treated with intrathecal streptomycin were examined for any evidence of falsely high values.

\section{Experimental}

Streptomycin calcium chloride (Glaxo) and dihydrostreptomycin sulphate (Glaxa) were used in the present work. Both these substances are hygroscopic and a determination of moisture was made on each sample used for analysis. About $500 \mathrm{mg}$. of the sample were accurately weighed in a porcelain boat and the loss in weight determined after heating for three hours at $60^{\circ} \mathrm{C}$. over phosphorus pentoxide under a reduced pressure of $10 \mathrm{~mm}$. Hg.

Solutions of streptomycin calcium chloride and dihydrostreptomycin sulphate in distilled water, ranging in concentration from 10 to $500 \mathrm{mg}$. per $100 \mathrm{ml}$. of the respective bases, were prepared and $1 \mathrm{ml}$. of copper reagent (Nelson, 1944) was added to $1 \mathrm{ml}$. of a 1 in 10 dilution of each concentration, and to $1 \mathrm{ml}$. of a $4 \mathrm{mg}$. per $100 \mathrm{ml}$. solution of glucose. The mixture was immersed in boiling water for 20 minutes, cooled, and $2 \mathrm{ml}$. of the Nelson arseno-molybdate chromogen added, followed by $8.5 \mathrm{ml}$. water. The optical 
densities were measured in a Spekker photoelectric absorptiometer against a reagent blank in which $1 \mathrm{ml}$. of water was substituted for the streptomycin or glucose solution, using a $1 \mathrm{~cm}$. cell and an Ilford spectrum red No. 608 filter.

\section{Results}

The reducing power of anhydrous streptomycin base in terms of milligrammes of glucose, using the Nelson method of estimation, is shown in Fig. 1; $1 \mathrm{mg}$. of glucose is equivalent to approximately $8 \mathrm{mg}$. of anhydrous streptomycin base; dihydrostreptomycin showed no reducing action in the Nelson method.

Typical cerebrospinal fluid glucose values observed in a case of treated tuberculous meningitis (a 31-year-old child) are shown in Fig. 2. The treatment, which began on Day 1, consisted of daily intrathecal injections of $50 \mathrm{mg}$. of streptomycin

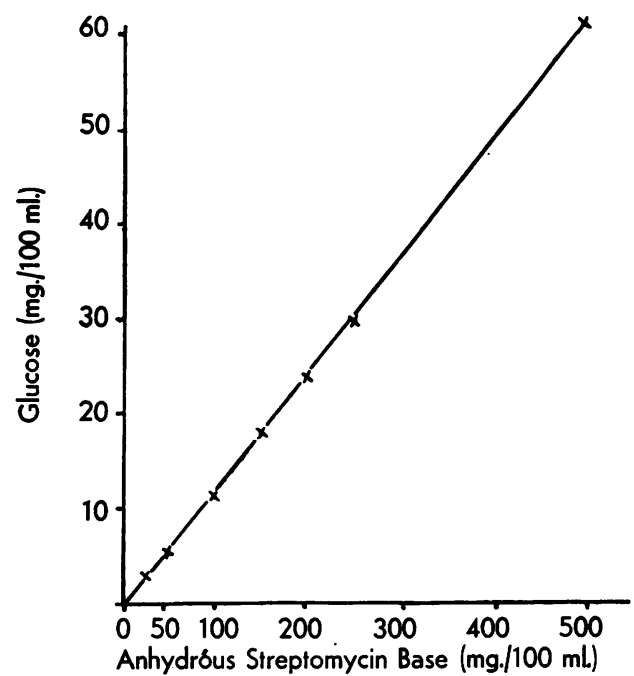

FIG. 1.-Glucose equivalent of anhydrous strepto-

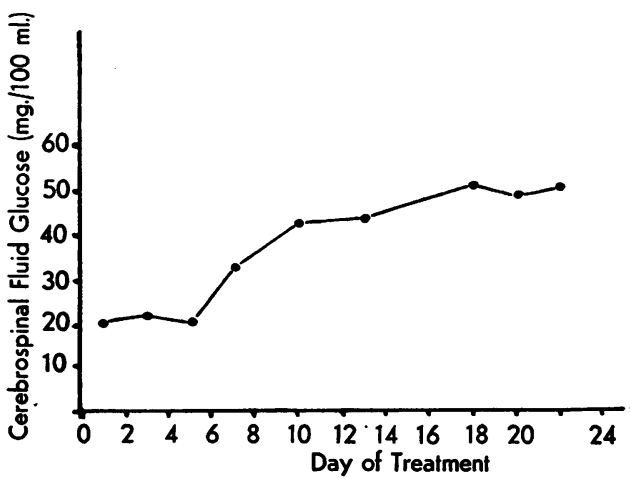

Fig. 2.-Cerebrospinal fluid glucose results in

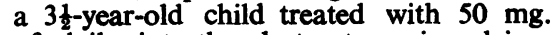
of daily intrathecal streptomycin calcium chloride from Day 1 onwards.

calcium chloride and 6 units of streptokinase, twice-daily intramuscular injections of $0.25 \mathrm{~g}$. of streptomycin calcium chloride, and $1.5 \mathrm{~g}$. of para-aminosalicylic acid every two and a half hours by mouth. Samples of cerebrospinal fluid for glucose analysis were withdrawn immediately before the injection of streptomycin and fluoride was added to inhibit glycolysis.

\section{Discussion}

The ratio $8 \mathrm{mg}$. of anhydrous streptomycin base to $1 \mathrm{mg}$. of glucose in the Nelson method means that a concentration of over $50 \mathrm{mg}$. per $100 \mathrm{ml}$. of streptomycin in cerebrospinal fluid is necessary before any significant interference with glucose measurements is produced. Samples of cerebrospinal fluid for analysis are normally taken 24 hours after the injection of 50 or $100 \mathrm{mg}$. of a streptomycin preparation. In both children and adults it was found (M.R.C. Report, 1948) that, one to three hours after the intrathecal injection of $100 \mathrm{mg}$. of streptomycin, the cerebrospinal fluid streptomycin level was between 75 and $200 \mathrm{mg}$. per $100 \mathrm{ml}$., but fell rapidly 
between four and 10 hours and was between 0.2 and $1.6 \mathrm{mg}$. per $100 \mathrm{ml}$. (range 0.1 to 7.5) 24 hours after the injection. Russell and MacArthur (1950) could not detect any streptomycin in the cerebrospinal fluid 24 hours after the intrathecal injection of $50 \mathrm{mg}$. of streptomycin in a child.

It must be concluded that the intrathecal injection of streptomycin preparations in the doses normally employed will not give artificially high values for glucose in samples of cerebrospinal fluid obtained 24 hours after injection and analysed by the method of Nelson.

Confirmation of this conclusion was found when the cerebrospinal fluid glucose values of treated cases were examined; for example, in Fig. 2, which represents a typical case, there was a period of five days before the glucose figure began to rise significantly, whereas, if streptomycin affected the result, an elevation would have been observed much sooner. Wilson (1951) reported a case of Staphylococcus aureus meningitis in which the cerebrospinal fluid glucose rose from $33 \mathrm{mg}$. per $100 \mathrm{ml}$. to $55 \mathrm{mg}$. per $100 \mathrm{ml} .24$ hours after the intrathecal injection of $100 \mathrm{mg}$. of dihydrostreptomycin sulphate, and suggested that the increased glucose value was due to the antibiotic. The method of estimation of cerebrospinal fluid glucose used by this author was not recorded, but in the present work dihydrostreptomycin was found to have no reducing action in the Nelson procedure. Alvaro and Nicola (1948), using the Hagedorn-Jensen method, stated that $1 \mathrm{mg}$. of streptomycin was equivalent to values of 0.32 to $4.5 \mathrm{mg}$. of glucose and quoted a value of 0.44 found by Nitti and Curci (1947). They also observed an immediate and steady rise in cerebrospinal fluid glucose values in cases treated with intrathecal streptomycin.

\section{Summary}

The reducing power of streptomycin and dihydrostreptomycin on the reagents used in the Nelson method for cerebrospinal fluid glucose has been investigated.

Dihydrostreptomycin has no reducing action, and approximately $8 \mathrm{mg}$. of anhydrous streptomycin base are equivalent to $1 \mathrm{mg}$. of glucose.

It is concluded that neither dihydrostreptomycin nor streptomycin will cause falsely high values for cerebrospinal fluid glucose in cases of tuberculous meningitis receiving these antibiotics by intrathecal injection.

I wish to express my gratitude to Dr. W. P. H. Sheldon for permission to publish the data in Fig. 2.

\section{REFERENCES}

Alvaro, M., and Nicola, M. (1948). Riv. Clin. pediat., 46, 372.

Cruickshank, D. B. (1951). Recent Advances in Clinical Pathology, ed. S. C. Dyke, 2nd ed., p. 43. London.

Medical Research Council (1948). Streptomycin in Tuberculosis Trials Committee. Lancet, 1, 582. Nelson, N. (1944). J. biol. Chem., 153, 375.

Nitti, V., and Curci, G. (1947). Arch. Tisiol., 2, 667.

Russell, S. J. M., and MacArthur, P. (1950). Lancet, 1, 59.

Wilson, H. (1951). Brit. med. J., 1, 1206.

[Observations have also been made using the Hagedorn-Jensen method. Varying concentrations of streptomycin and dihydrostreptomycin were dissolved in pooled normal cerebrospinal fluid and titrated in the ordinary way. Using 
dihydrostreptomycin (Glaxo) up to 1,000 $\mu \mathrm{g}$. per ml., no change in reducing power of cerebrospinal fluid was found.

With streptomycin (Glaxo), two different batches gave excess reduction due to the streptomycin, equivalent to 28 and $36 \mathrm{mg}$. glucose per $100 \mathrm{ml}$. when present in a concentration of $1,000 \mu \mathrm{g}$. per ml.; with streptomycin concentrations of 100 and $200 \mu \mathrm{g}$. per $\mathrm{ml}$., the rise was equivalent only to $4-6 \mathrm{mg}$. glucose per $100 \mathrm{ml}$.

Very high levels of streptomycin are only present a very short time after an intrathecal injection, and these findings, unlike those of Alvaro and Nicola, suggest that the administration of streptomycin is unlikely to cause any unreliability in cerebrospinal fluid sugar levels unless the cerebrospinal fluid is taken only a few hours after the last injection.-ED.] 